\title{
Characteristics of colony growth from normal human bone marrow
}

\author{
T. C. M. MORRIS, T. A. McNEILL, AND J. M. BRIDGES \\ From the Department of Microbiology, The Queen's University of Belfast, and the Department of \\ Haematology, Royal Victoria Hospital, Belfast
}

SYNOPSIS The number of granulocyte/macrophage colonies grown in vitro from bone marrow cells obtained from 90 rib segments and 30 'normal' bone marrow aspirates was found to be highly variable. Considerable variation was also noted in the relationship between colony number and the number of cells cultured in both groups. The aspirate group was found to have a significantly greater ability to form colonies without the addition of colony-stimulating factor to the culture medium at low cell concentrations.

The technique whereby colonies of granulocyte and monocyte/macrophage cells can be grown from their progenitor cells (colony-forming cells) in soft agar culture has been very extensively studied in the experimental animal. In this situation colony growth is dependent on the presence of a colony-stimulating factor in the culture system. The potential application of this technique to human myelopoiesis, both normal and disordered, is twofold, in that the granulopoietic potential of a marrow sample may be assessed and biological fluids can be assayed for their content of stimulating and inhibiting substances (Metcalf, 1973).

While the growth characteristics of marrow cells in small rodents has been extensively studied, much less work has been done to establish the pattern of colony growth from normal marrow cells in the human subject. A major problem in this regard is the difficulty of obtaining marrow samples from normal donors and most work has been done on material aspirated from patients subsequently shown not to have any haematological abnormality. Another source of marrow cells would be from the portions of rib removed routinely at thoracotomy and in this paper we report on the characteristics of growth from 90 such samples taken from patients not suffering from any haematological disorder. For purposes of comparison, a study of 30 samples obtained by aspiration was also made.

Received for publication 5 August 1974.

\section{Materials and Methods}

CELL COLLECTION

Bone marrow cells from surgical patients (rib group) were obtained from small segments of fifth rib removed routinely at thoracotomy and also from some portions of 12 th rib removed during major renal surgery; all patients had no primary haematological disorder. The rib segment was placed in collecting medium (BHK Eagle's, Wellcome Reagents Ltd) supplemented with $10 \%$ fetal calf serum (Flow Laboratories Ltd) and 10\% trypticase soy broth (Difco) and the cells were suspended after washing medium through the medullary cavity with a Sahli marrow biopsy needle attached to a syringe. Smears for differential counting were prepared by re-suspending a centrifuged pellet in a drop of serum and staining by May-Grunwald Giemsa.

Samples of marrow aspirated from the anterior iliac crest were placed in bottles containing $5 \mathrm{ml}$ collecting medium (with $100 \mu$ preservative-free heparin: Weddel Pharmaceuticals Ltd, London). The marrow donors in this group were patients who had undergone marrow biopsy for investigative purposes which subsequently revealed no significant haematological disorder. Excess erythrocytes were removed by layering the diluted sample over methylcellulose/triosil (Hullinger and Blaztiovec, 1967) and allowing them to sediment at room temperature for 30 to 50 minutes. The leucocyte-rich supernatant was removed and nucleated cell counts performed. 


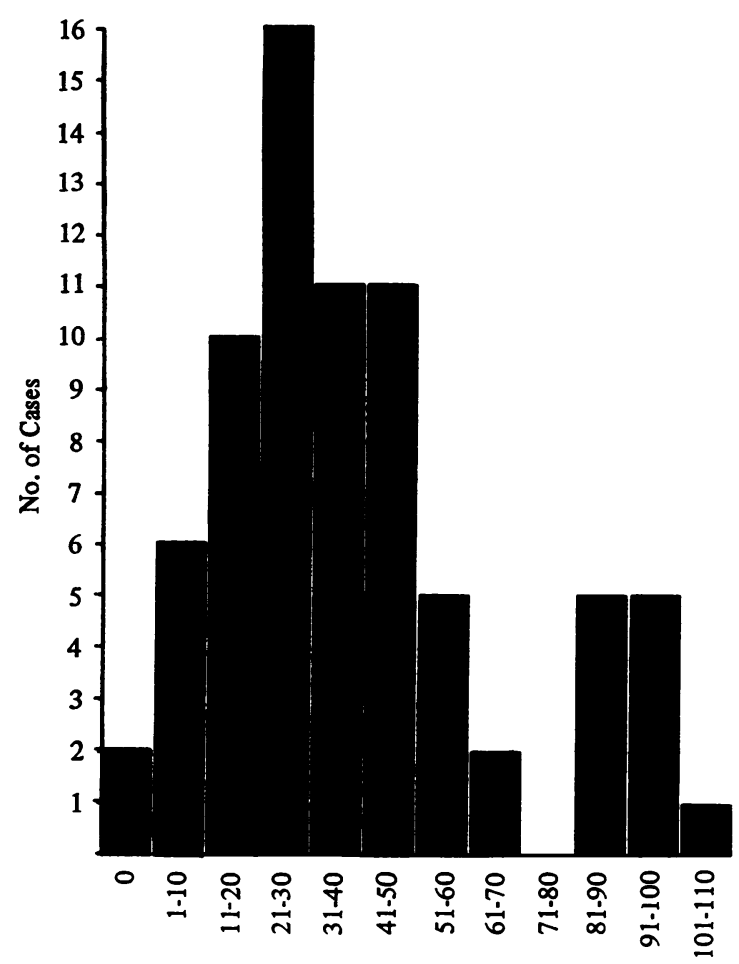

(a) No. of Colonies of $1 \times 10^{5}$ Bone Marrow Cells per Culture

Fig 1 Histogram of numbers of colonies per culture from rib samples cultured at (a) $1 \times 10^{5}$ marrow cells per culture; (b) $1 \times 10^{6}$ marrow cells per culture.
Samples in which the total cell count was less then $1 \times 10^{7}$ were discarded.

CULTURE OF COLONY-FORMING CELLS

All cultures were performed by the double-layer technique in Nunclon $30 \mathrm{~mm}$ plastic dishes using the modified Eagle's medium previously described (McNeill, 1971). In brief, a $2 \mathrm{ml}$ underlayer of Eagle's $1.2 \%$ agar was placed in each dish. Colonystimulating factor was provided by the inclusion of $5 \%(\mathrm{v} / \mathrm{v})$ human embryo or human spleen cell conditioned medium in the underlayer. Eagle's $0.3 \%$ agar was held at $37^{\circ} \mathrm{C}$, cells were added to the appropriate concentration, and $1 \mathrm{ml}$ aliquots placed on the gelled underlayers. Cultures were routinely performed in quadruplicate at cell concentrations of $1 \times 10^{5}, 2.5 \times 10^{5}$ and $1 \times 10^{6}$ per $\mathrm{ml}$ with intermediate concentrations in some instances. Cultures were incubated for seven days at $37^{\circ} \mathrm{C}$ in sealed boxes containing $10 \% \mathrm{CO}_{2}$ in humidified air and colonies counted by a single observer at $\times \mathbf{4 0}$ magnification using an Olympus dissecting microscope. Aggregates of greater than 20 to 30 cells were scored as colonies.

\section{Results}

The contents of both rib and aspirate marrow samples with particular regard to cells of the granulocytic series, are shown in table I. The mature polymorph content of the aspirated group was higher than the rib group but the proportions were otherwise fairly

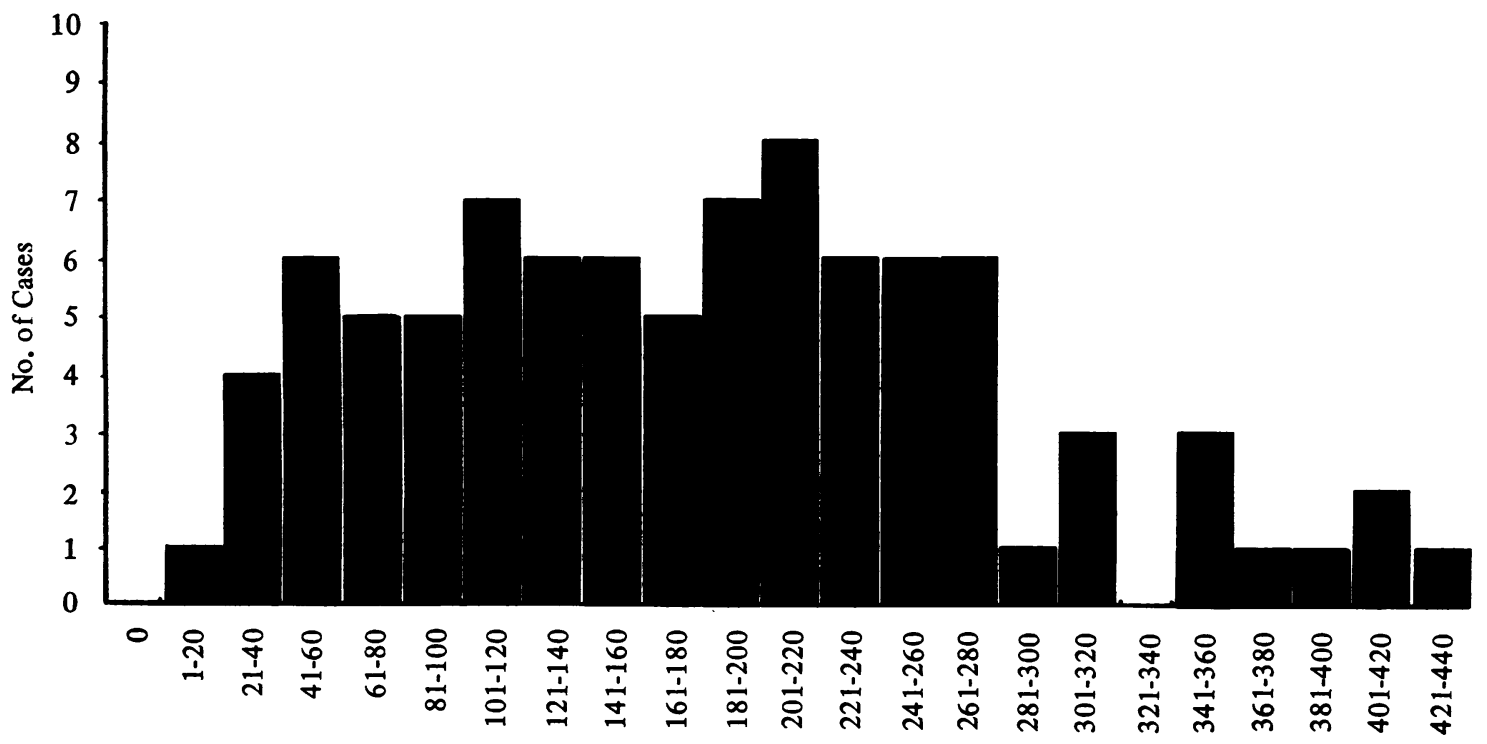

(b) 


\begin{tabular}{|c|c|c|c|c|c|c|}
\hline \multirow[t]{2}{*}{ Cell Type } & \multicolumn{2}{|c|}{ Mean } & \multicolumn{2}{|l|}{$S D$} & \multicolumn{2}{|l|}{ Range } \\
\hline & $R i b$ & Aspirate & $R i b$ & Aspirate & $R i b$ & Aspirate \\
\hline Blast & $3 \cdot 3$ & $2 \cdot 9$ & $1 \cdot 1$ & 0.9 & $0.8-5.6$ & $1 \cdot 5-4 \cdot 2$ \\
\hline Promyelocyte & 1.8 & 1.4 & 0.6 & $1 \cdot 1$ & $1 \cdot 0-3.0$ & $0.6-3.5$ \\
\hline Myelocyte & 145 & $13 \cdot 6$ & $2 \cdot 3$ & $4 \cdot 3$ & $11 \cdot 2-18 \cdot 4$ & $4 \cdot 8-19 \cdot 2$ \\
\hline Metamyelocyte & $34 \cdot 1$ & $23 \cdot 5$ & $5 \cdot 6$ & $6 \cdot 0$ & $23 \cdot 8-42 \cdot 2$ & $14 \cdot 9-30 \cdot 2$ \\
\hline Polymorph & 6.7 & $19 \cdot 9$ & $2 \cdot 7$ & $5 \cdot 1$ & $3 \cdot 8-13 \cdot 1$ & $10 \cdot 4-29 \cdot 2$ \\
\hline Lymphocyte & $4 \cdot 7$ & $2 \cdot 8$ & 1.9 & 1.9 & $2 \cdot 1-9 \cdot 3$ & $0 \cdot 8-7 \cdot 2$ \\
\hline Monocyte & $3 \cdot 1$ & $2 \cdot 2$ & 1.6 & 1.6 & $1 \cdot 2 \cdot 7 \cdot 0$ & $0.6-4.8$ \\
\hline Erythroblast & $30 \cdot 3$ & $33 \cdot 5$ & $5 \cdot 8$ & $6 \cdot 7$ & $16 \cdot 8-42 \cdot 0$ & $23 \cdot 8-47 \cdot 0$ \\
\hline Plasma cell & 0.9 & 0.8 & 0.6 & 0.5 & $0 \cdot 2 \cdot 2 \cdot 6$ & $0-1 \cdot 2$ \\
\hline Reticulum cell & $0 \cdot 3$ & 0.5 & 0.3 & 0.4 & $0 \cdot 1 \cdot 2$ & $0-1.0$ \\
\hline
\end{tabular}

Table I Results of differential marrow counts performed on 16 rib and 16 aspirate specimens

similar; rib marrow would seem to provide only a marginally more constant sample.

\section{RIB GROUP}

Figure 1 shows the number of colonies per culture when marrow cells were plated at $1 \times 10^{5}$ (fig 1a, 79 samples) or $1 \times 10^{6}$ (fig $1 \mathrm{~b}, 90$ samples). Colonystimulating factor was added to all cultures. The mean colony number was 39 at $1 \times 10^{5}$ (range $0-102$, SD \pm 27 ) and 179 at $1 \times 10^{6}$ (range $1-423$, SD \pm 100). Analysis of clinical data from these patients in terms of diagnosis, peripheral blood leucocyte count, and body temperature revealed no correlation between these parameters and the capacity for colony growth by marrow cells. No single cell type shown in table I was found to have a direct relationship with the colony count.

Clearly in terms of absolute counts these results

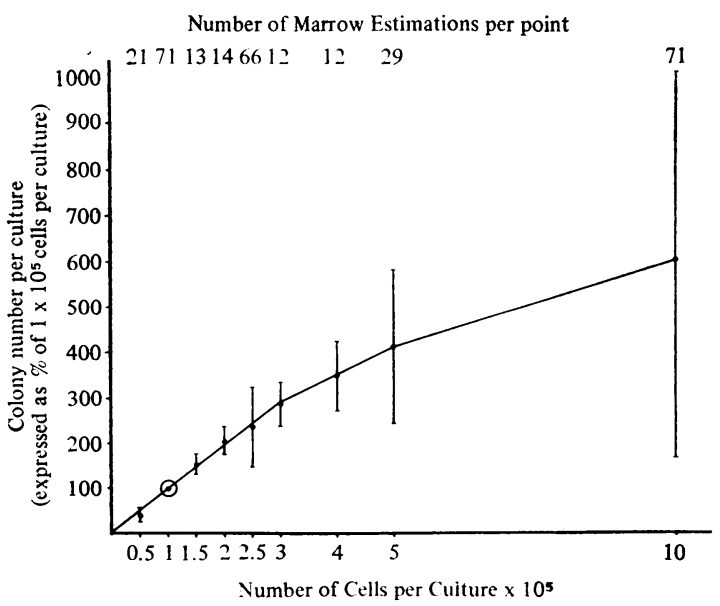

Fig 2 Relationship between colony number and marrow cells per culture, standardizing data from each individual rib sample by taking colony number at $1 \times 10^{5}$ as 100. All other counts expressed as mean and standard deviation relative to this. show great variation between individuals. In fig 1 the two samples which failed to grow colonies at $1 \times 10^{5}$ also gave poor growth at $1 \times 10^{6}$ but in samples with more profuse growth $(11>80$ colonies at $1 \times 10^{5}$ and $12>280$ colonies at $1 \times 10^{6}$ ) only four individuals were common to both. The data indicated that colony number was not directly proportioned to the number of cells plated. Figure 2 shows the relationship between colony number and

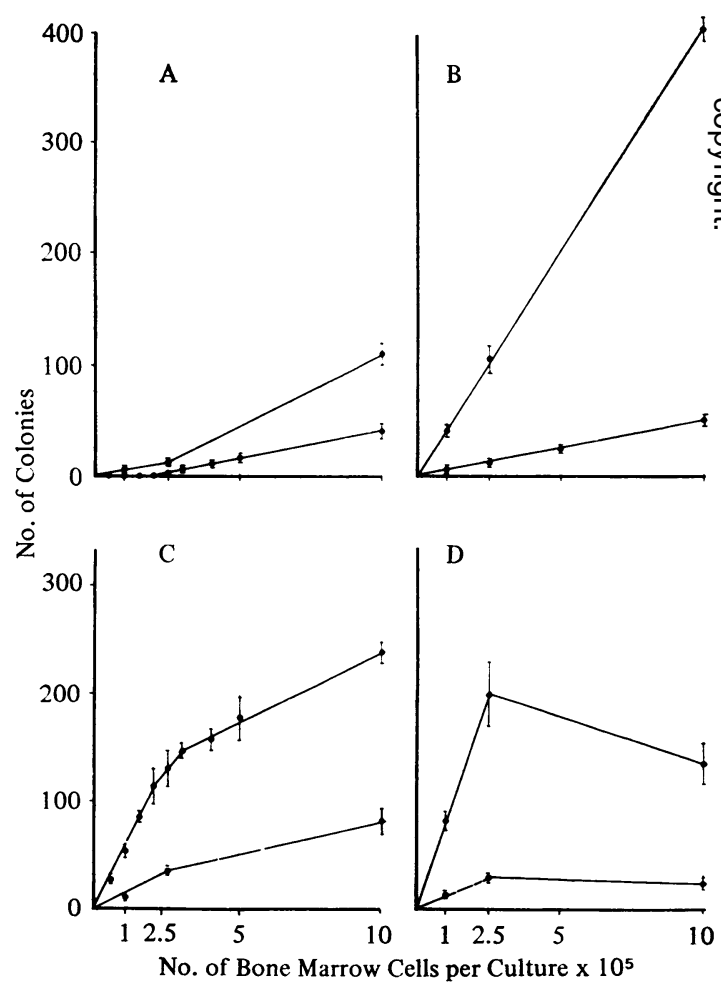

Fig 3 Graphs showing the relationship between number of bone marrow cells per culture and colony number for individual rib samples. Mean $\pm S D$ of colony count from groups of four cultures at each cell concentration. Results of two separate marrows are shown on each graph. 


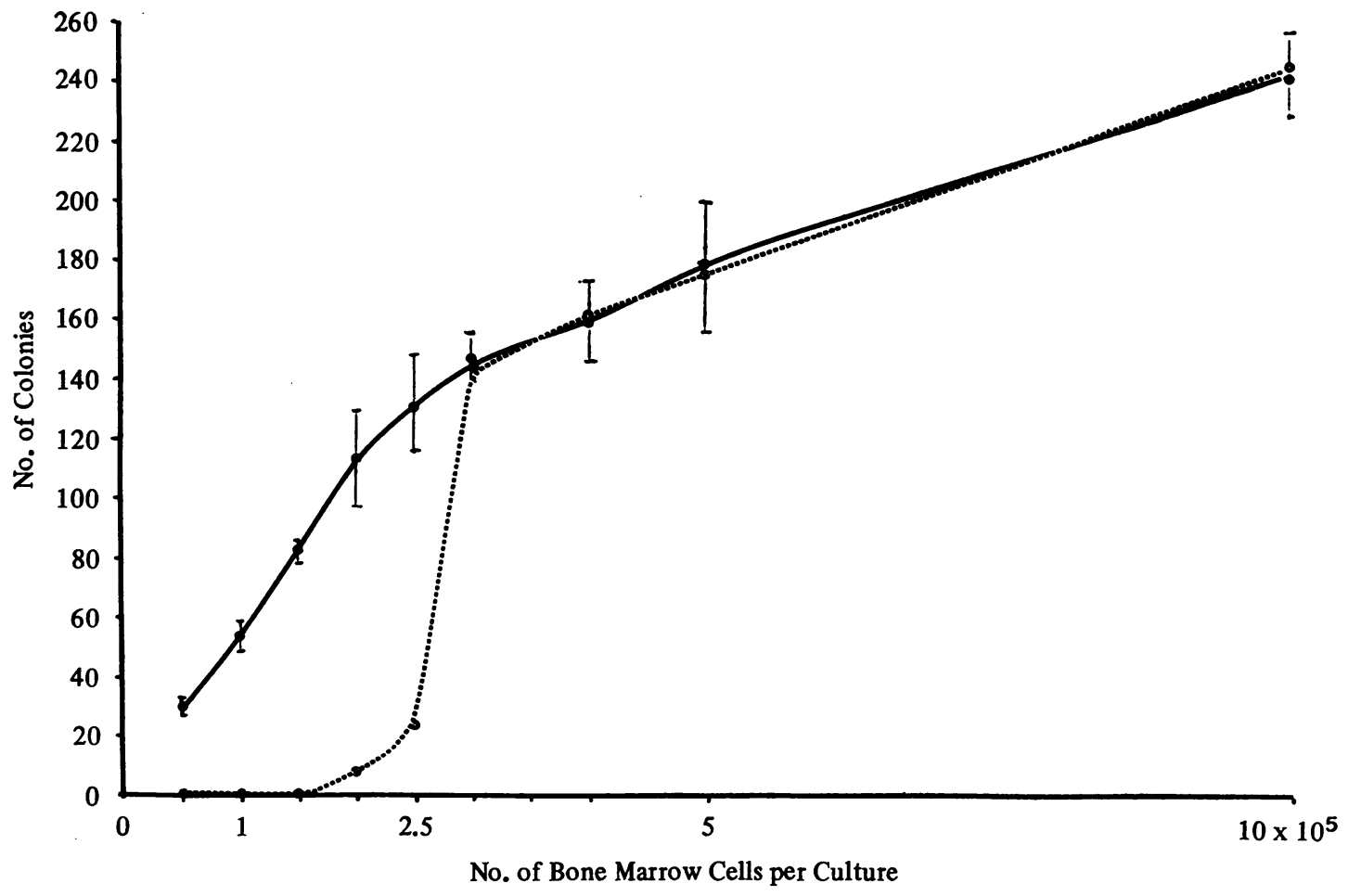

Fig 4 Spontaneous colony formation. Points joined by the continuous line represent the mean $\pm S D$ of four replicate cultures in which colony-stimulating factor was added to the cultures. The discontinuous line joins points observed when extraneous colony-stimulating factor was omitted from the cultures.

the number of cells per culture, standardizing the data from each individual sample by taking the colony number at $1 \times 10^{5}$ as 100 and expressing counts at other cell concentrations relative to this. Each marrow was not cultured at every cell concentration and the number of estimations for each point is shown. It can be seen that lack of proportionality between colony number and number of cells plated was a feature of normal marrow cultures. This analysis, however, fails to demonstrate the different patterns of individual marrows in which four separate groups could be identified by plotting individual graphs; fig 3 demonstrates two examples for each of these variations. The majority (57 out of 77 suitable for analysis) gave the type of non-linear relationship shown by the averaged data of fig 2 , eg, fig 3c. A further four samples gave a count at $1 \times 10^{6}$ cells per culture, which was lower than at either $2.5 \times 10^{5}$ or $5 \times 10^{5}$ cells per culture (fig $3 \mathrm{~d}$ ). Thirteen of the samples showed a direct proportionality up to and including $1 \times 10^{6}$ cells per culture (fig 3b), while three individuals showed disproportionately high colony counts at $1 \times 10^{6}$ cells per culture in relation to lower cell counts (fig 3a).

Parallel cultures were made in which extraneous colony-stimulating factor was omitted and colony counts in these cultures showed that below a critical cell concentration the count fell rapidly to zero; a single example is shown in figure 4. This cell concentration at which spontaneous colony formation occurred varied from marrow to marrow (usually within the range 1 to $5 \times 10^{5}$ cells per culture) and was not related to the actual number of colonies growing at that cell concentration.

\section{ASPIRATED MARROW}

Results from cultures of 30 marrow samples taken by aspiration from the iliac crest are shown in fig 5 for comparison with the results for rib marrow (fig 1). The distribution of colony counts at $1 \times 10^{5}$ and $1 \times 10^{6}$ cells per culture was very similar to that shown for rib marrow. For aspirated marrow the mean colony counts were 45 at $1 \times 10^{5}$ (range $0-175, S D \pm 41$ ) and 174 at $1 \times 10^{6}$ (range $1-470$, $\mathrm{SD} \pm 121)$. 

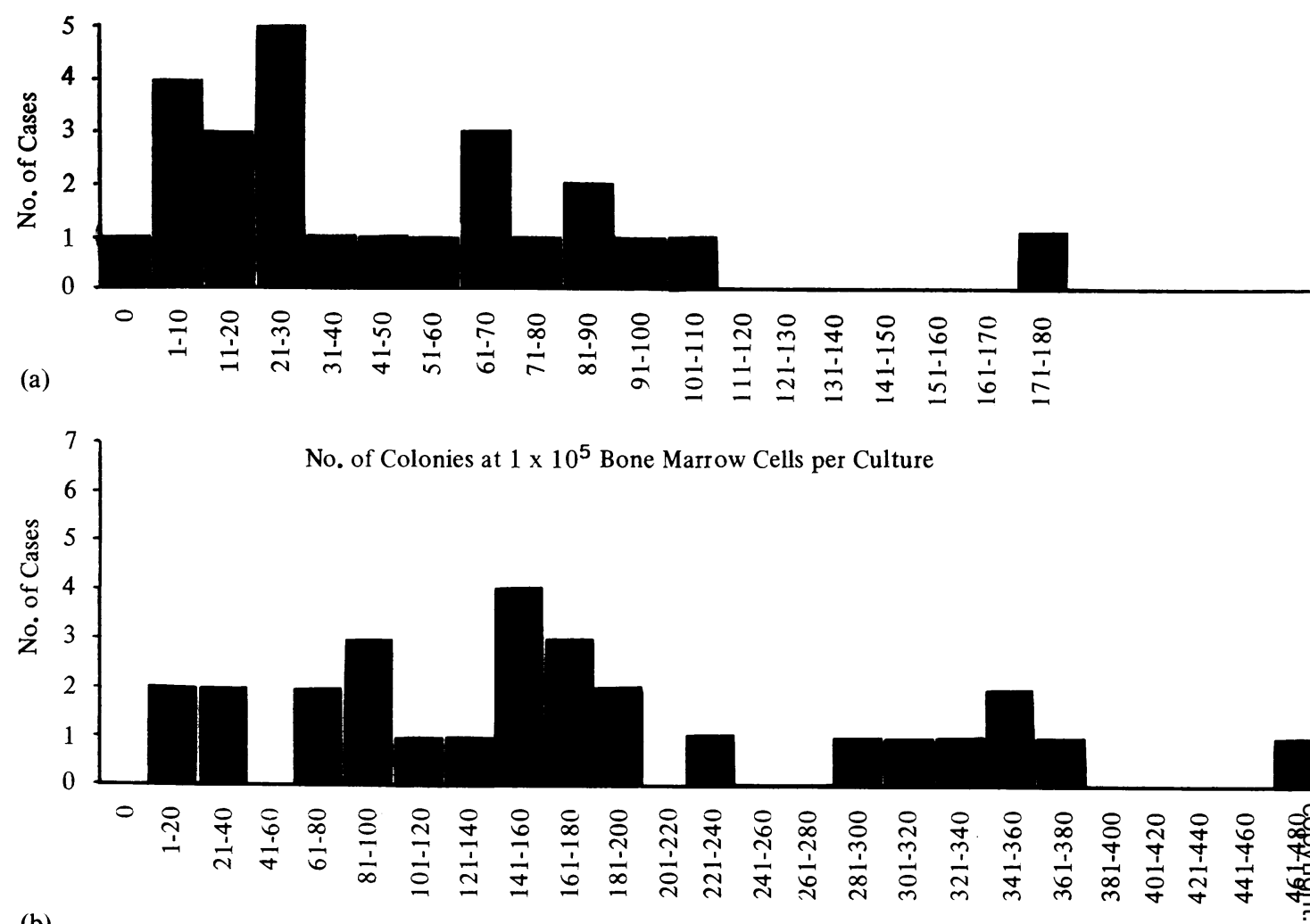

(b)

No. of Colonies of $1 \times 10^{6}$ Bone Marrow Cells per Culture

Fig 5 Histogram of numbers of colonies per culture from aspirated samples cultured at (a) $1 \times 10^{5}$ cells per culture;

(b) $1 \times 10^{6}$ marrow cells per culture.

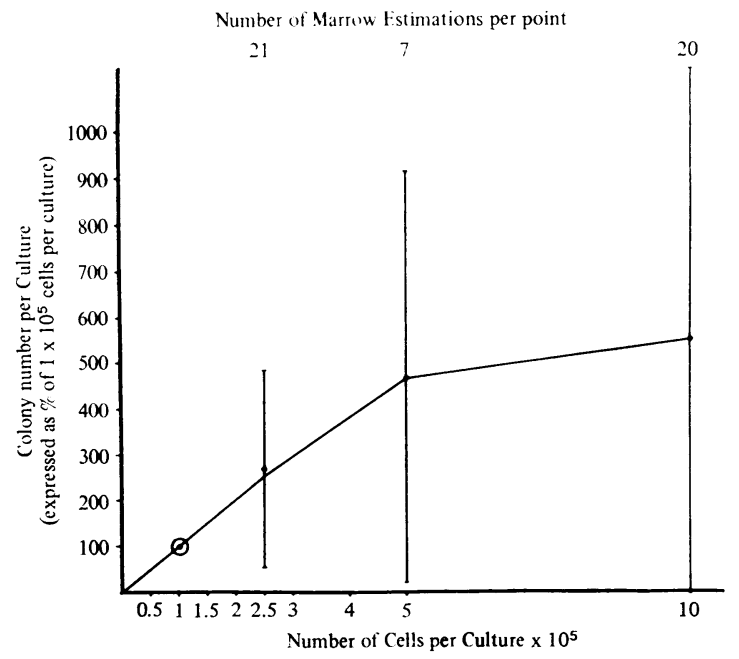

Fig 6 Relationship between colony number and marrow cells per culture, standardizing data from each individual aspirate sample by taking colony number at $1 \times 10^{5}$ as 100. All other counts expressed as mean and standard deviation relative to this.
Figure 6 gives the relationship between colony number and cell concentration for aspirated marrow using the same method of calculation as that for rib marrow in figure 2. The aspirated marrows showed a similar disproportionality between colony number and increasing cell concentration. As with the rib group, individual analysis once again showed that the majority of samples gave the type of non-linear relationship demonstrated in figs 2 and 6 but individual examples of each of the types described in fig 3 were also found.

With regard to the requirement for added colonystimulating factor, aspirated marrow showed a greater ability to form colonies spontaneously in cultures containing lower cell concentrations when compared with rib marrow. This is shown in table II, which gives for different cell concentrations the dis- $\cong$ tribution of specimens from rib and aspirated marrow in which unstimulated cultures gave either equal, reduced, or no colony growth compared with stimulated cultures. Because of the small numbers of samples in some of the groups the $\chi^{2}$ test could 


\begin{tabular}{|c|c|c|c|c|c|c|c|c|}
\hline & \multicolumn{2}{|c|}{$1 \times 10^{5}$} & \multicolumn{2}{|c|}{$2.5 \times 10^{5}$} & \multicolumn{2}{|c|}{$5 \times 10^{5}$} & \multicolumn{2}{|c|}{$1 \times 10^{6}$} \\
\hline & $R i b$ & Aspirate & Rib & Aspirate & Rib & Aspirate & Rib & Aspirate \\
\hline $\begin{array}{l}\text { Number of samples } \\
\text { Growth equal to stimulated }\end{array}$ & 66 & 24 & 68 & 25 & 36 & 12 & 75 & 25 \\
\hline $\begin{array}{l}\text { plates } \\
\text { Growth less than stimulated }\end{array}$ & 1 & 2 & 11 & 10 & 16 & 8 & 59 & 21 \\
\hline $\begin{array}{l}\text { plates } \\
\text { No growth }\end{array}$ & $\begin{array}{r}7 \\
58\end{array}$ & $\begin{array}{r}7 \\
15\end{array}$ & $\begin{array}{l}35 \\
22\end{array}$ & $\begin{array}{l}9 \\
6\end{array}$ & $\begin{array}{r}12 \\
8\end{array}$ & $\begin{array}{l}3 \\
1\end{array}$ & $\begin{array}{r}11 \\
5\end{array}$ & $\begin{array}{l}3 \\
1\end{array}$ \\
\hline $\mathbf{P}^{1}$ & \multicolumn{2}{|c|}{0.0185} & \multicolumn{2}{|c|}{0.0636} & \multicolumn{2}{|c|}{0.4567} & \multicolumn{2}{|c|}{1.000} \\
\hline
\end{tabular}

Table II Comparison of spontaneous colony formation in rib and aspirate samples

${ }^{1} \mathrm{P}$ analysed by the exact probability test shows a significantly greater degree of spontaneous colony formation by aspirated marrow at $1 \times 10^{5}$ cells per culture.

not be utilized and the figures were analysed using the exact probability test. At a cell concentration of $1 \times 10^{5}$ the values for $P$ show a significant difference $(P=0.0185)$, indicating a greater degree of spontaneous colony formation in the aspirate group.

\section{Discussion}

Our results from cultures of rib marrow taken from non-haematological patients showed a wide variation in colony-forming capacity between individuals. This was not reflected in differing content of granulocytic precursors in the samples as judged by examination of Giemsa-stained preparations, since these lay within relatively narrow ranges (table I). Similar variations in colony number have been reported by others in smaller series of marrow aspirates (table III).

\begin{tabular}{lllll}
\hline Reference & Date & $\begin{array}{l}\text { No. of } \\
\text { Samples }\end{array}$ & $\begin{array}{l}\text { Cell } \\
\text { Concentration }\end{array}$ \\
\hline Senn et al & 1967 & 15 & $1 \times 10^{5}$ & $15-50$ \\
Harris and Freireich & 1970 & 6 & $1 \times 10^{\circ}$ & $26-410$ \\
Brown and Carbone & 1971 & 17 & $2 \times 10^{5}$ & $8-48$ \\
Greenberg et al & 1971 & 37 & $1 \times 10^{5}$ & $14-126$ \\
Greenberg and Schrier & 1973 & 22 & $1 \times 10^{5}$ & $14-36$ \\
Moore et al & $1973(a)$ & 6 & $2 \times 10^{5}$ & $13-90$ \\
\hline
\end{tabular}

Table III Culture of marrow aspirates from non-

haematological patients

Colony growth from marrow samples obtained by aspiration gave essentially the same mean values and showed the same degree of variation as that from rib samples. It is clear, therefore, that variation introduced by the method of sampling is a minor factor in the observed variation of results for colonyforming capacity. The fact that colony number was often not proportional to the number of marrow cells plated (figs 2 and 3 ) also limits the value of any figure for colony-forming potential in a given marrow, particularly since the degree of disproportionality at higher cell concentrations varied from marrow to marrow (fig 3). Rib and aspirate marrows had similar characteristics with regard to this disproportionality.
These characteristics of human colony growth can obviously lead to difficulties in the interpretation of results from patients with haematological disease. For example, we have found (unpublished data) that colony counts from cultures of marrow from patients with acute lymphoblastic leukaemia in remission were significantly lower than normal when cultured at $10^{6}$ cells per culture but there was no significant difference between the groups when cultures containing $10^{5}$ cells were used.

Taken together these results show that a simple estimation of colony-forming cells in a single marrow sample is unlikely to be of value in assessing the granulopoietic capacity of an individual. Further investigations are necessary to establish whether or not sequential samples from the same individual over a period of time would yield more informative results.

Human marrow cells, like cells from most other species, show some colony formation in the absence of added colony-stimulating factor. This is due to the presence of colony-stimulating factor-producing cells in these populations (Moore and Williams, 1972). In a small series, which included samples from two normal individuals, Moore, Williams, and Metcalf (1973b) showed that spontaneous colony formation was dependent upon the cell concentration and usually occurred when this was in the range of 1 to $5 \times 10^{5}$ cells per culture. The present observations confirm this finding with a much larger number of normal samples. A point of difference was noted between the rib aspirate groups-spontaneous colony formation was significantly greater in the aspirate group at cell concentrations below $2.5 \times 10^{5}$ cells $/ \mathrm{ml}$ (table II).

We are indebted to Professor M. G. Nelson for allowing us to study material from patients under his care, to $\mathrm{Mr} \mathbf{H}$. M. Stevenson for providing rib samples, and to Mrs H. Jess for technical assistance.

This work was carried out whilst T.C.M.M. was in receipt of a Royal Victoria Hospital, Belfast, research fellowship. 
References

Brown, C. H., III, and Carbone, P. P. (1971). In vitro growth of normal and leukemic human bone marrow. J. nat. Cancer Inst., 46, 989-1000.

Greenberg, P. L., Nichols, W. C., and Schrier, S. L. (1971). Granulopoiesis in acute myeloid leukaemia and preleukemia. New Engl. J. Med., 284, 1225-1232.

Greenberg, P. L., and Schrier, S. L. (1973). Granulopoiesis in neutropenic disorders. Blood, 41, 753-769.

Harris, J., and Freireich, E. J. (1970). In vitro growth of myeloid colonies from bone marrow of patients with acute leukemia in remission. Blood, 35, 61-63.

Hullinger, L., and Blaztiovec, A. A. (1967). A simple and efficient method of separating peripheral blood leucocytes for in vitro studies. Lancet, 1, 1304-1305.

McNeill, T. A. (1971). The effect of synthetic double-stranded poly- ribonucleotides on haemopoietic colony-forming cells in vitro. Immunology, 21, 741-750.

Metcalf, D. (1973). Human leukaemia: Recent tissue culture studies 을 on the nature of myeloid leukaemia. Brit.J. Cancer, 27, 191-202.

Moore, M. A. S., and Williams, N. (1972). Physical separation of $\mathcal{G}$ colony stimulating cells from in vitro colony forming cells in hemopoietic tissue. J. Cell Physiol., 80, 195-206.

Moore, M. A. S., Williams, N., and Metcalf, D. (1973a). In vitro colony formation by normal and leukemic human hematopoietic cells: characterization of the colony-forming cells. J. nat. Cancer Inst., 50, 603-623.

Moore, M. A. S., Williams, N., and Metcalf, D. (1973b). In vitro colony formation by normal and leukemic human haemato- $s$ poietic cells: interaction between colony-forming and colony-stimulating cells. J. nat. Cancer Inst., 50, 591-602.

Senn, J. S., McCulloch, E. A., and Till, J. E. (1967). Comparison of colony-forming ability of normal and leukemic human marrow in cell culture. Lancet, 2, 597-598.

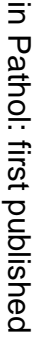

